\title{
Guyana diary
}

\author{
By Mignon G. Adams \\ Coordinator of Information Services \\ State University of New York-Oswego
}

\section{The challenges of consulting in a Third World country.}

\begin{abstract}
A believing that we cope with major probloms of insufficient staff and money, unprepared students, and inadequate collections. However, a monthlong stint as a consultant at the University of Guyana Library gave me a fresh perspective on the problems of my library and an appreciation of the wealth of resources available to us.

Guyana is more than Jim Jones and his tragic cult. Located on the northern coast of South America, but culturally part of the Caribbean, Guyana is a former British colony which has chosen socialism. Like many developing nations, the country has severe foreign exchange problems: virtually all imports (including wheat as well as books) have been stopped.

The University of Guyana, located just outside the capital of Georgetown, is the only university in the country. It provides programs in liberal arts, agriculture, and engineering to 2,000 students. Higher education is free although all students must perform a year of national service, usually in the military. As a result there are few non-Guyanese students.
\end{abstract}

With 150,000 volumes, the library at UG is by far the largest library in the country. Its staff of 12 librarians has been trained primarily in England, with younger librarians more likely to have completed a diploma program at the University of the West Indies in Jamaica. Both staff and students reflect the two major ethnic groups, African and East Indian.

A total of 80 staff members seems a large number to us for a library that size. However, student workers are not used at all; any binding to be done must be performed in-house; and tight security is necessary in a country where books are far more valuable than in ours. That number includes the cleaning staff as well, who view as part of their jobs picking fresh flowers on the way to work and arranging them on librarians' desks.

Officially my role under the U.S. Information Agency grant which supported my visit was to advise and consult with the library staff on bibliographic instruction-or user education, the more common term in countries under British influence. In addition, I was called upon to offer advice and support in many areas of library services. Since, as a result of import restrictions, the library's acquisitions had been virtually halted two years previously, a major concern was to make the few up-todate materials go as far as possible.

User education begins at a very basic level. Some entering freshmen may have used the Guyana Public Library or the USIA library. If not, they may have used libraries limited only to a bookcase or two and have no familiarity with card catalogs or even encyclopedias. Completely new to most students is the concept of using a variety of resources and referring to them in standard ways.

Plans were developed for enlarging the scope of the paraprofessional training program the UG library conducts for its own staff by offering it to all library employees in Georgetown. Many libraries in Guyana depend upon staff with no professional training for day-to-day operations. The program as we envisioned it would include an introduction to basic library procedures-simple cataloging, 


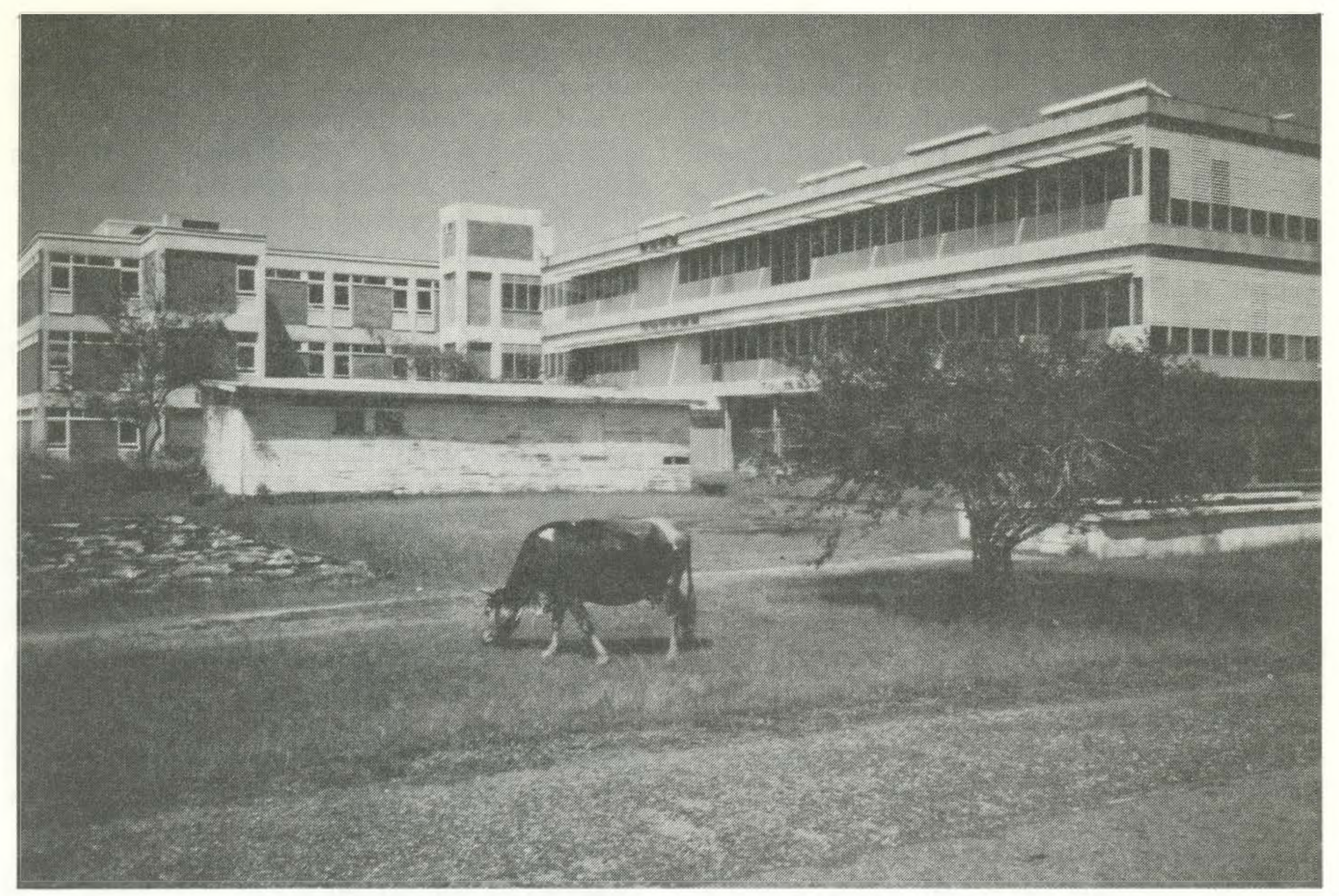

A symbol of Guyanese self-sufficiency, a cow grazes languidly outside the University of Guyana Library.

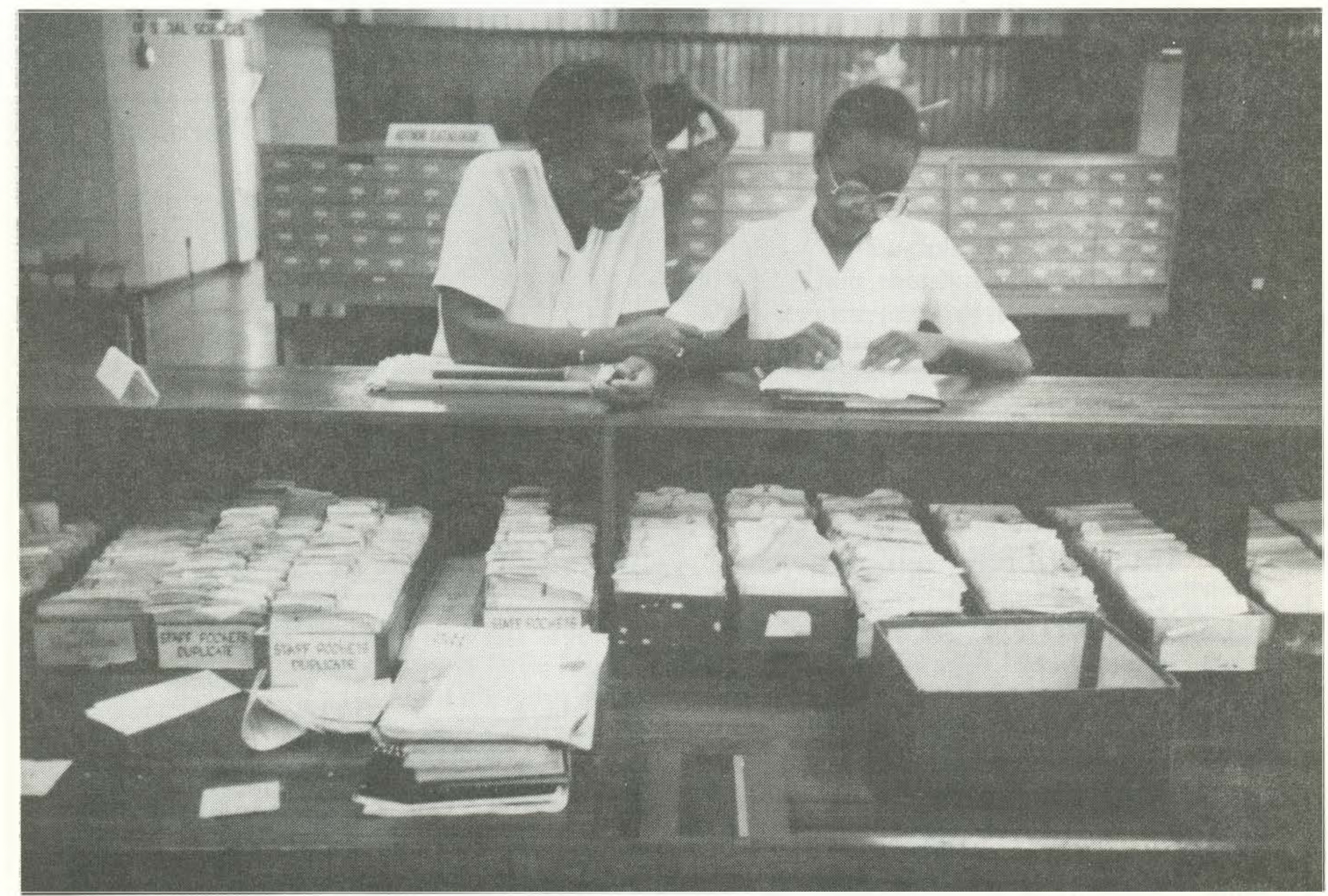

Inside the library, a student gets help from a reference librarian. 
reference, organization-as well as some training in management and supervision.

It was evident that I was in a socialist country. The formal term for referring to others is "Comrade," and while sociology is a major department at the university, psychology is taught only as a part of education. When I asked for examples of topics which students might be researching, responses were North Korean management methods, socialism as practiced in Cuba and Tanzania, and even (although tongue-in-cheek) the evils of capitalism. I had few suggestions for search strategy techniques for these topics.

Transportation is a major problem. Automobiles and parts also fall under import restrictions; those fortunate enough to have cars keep them running through positive thinking and mechanical wizardry. I, like most of the staff, commuted the twomile distance to the campus by hire-car, private cars licensed to drive on regular routes. One Guyanese dollar (the equivalent of 25 cents) got me a seat with four other passengers-more, if the Police were looking the other way-in a compact car, usually ten or more years old. An additional expense for the library is to provide taxitransportation for staff members who work at night and who otherwise would have no way at all to get home.

Environment is also a problem. One section of the library, that which contains the Caribbean collection, is air-conditioned. In the rest of the building, humid tropical weather quickly yellows paper and causes painted metal shelving to rust within ten years. Humid paper has trouble going through copiers. Even catalog cards develop foxing (brown spots). Insects, of course, are another major problem, and pesticides are in short supply. A pile of papers left on my bookcase had tiny neat holes bored through them, evidence of a worm at work.

Anything that must be imported is in short supply. For a library, that includes such basic supplies as staples, catalog cards, band-aids, and even toilet paper. The binding staff is experimenting with cassava paste as a substitute for glue with fairly good results.

What is not a problem, however, is the dedication and knowledge of the staff. I found library staff and university faculty members to be well-

\section{International exchange}

ALA's IRC/IRRT Joint Committee on International Exchange of Librarians and Information Professionals is collecting information about librarians who have been involved in any type of international exchange. The committee hopes to compile a directory of such individuals. Please send relevant information to Hannelore B. Rader, Director, Library/Learning Center, University of Wisconsin-Parkside, Box 2000, Kenosha, WI 53141. educated, articulate, and much better informed on international affairs than I. Those who have decided to remain in Guyana rather than emigrating to more developed countries have chosen a commitment to creating a self-sufficient country even though that decision may mean a lower standardof-living for themselves and their families.

That Guyana is a Caribbean country was demonstrated at the staff Christmas party, which coincided with my last night in the country. All staff members were involved in the planning of food and music and decorations. Calypso records played from 9 p.m. to about $3 \mathrm{a} . \mathrm{m}$. The president of the university, as well as the registrar and several deans, were present and everyone danced. I was presented with a UG tee-shirt, which I promised to wear in upstate New York.

My personal gains from my stay in Guyana were enormous. I received an in-depth view of a third world country, not as a tourist but as a member of the regular working community. It is an experience I would recommend for any American librarian, as a way to contribute expertise and ideas while at the same time expanding understanding of developing countries and losing some of one's own provincialism. Libraries in developing countries often have vacancies for which there are no local candidates. While grants are seldom available, librarians eligible for sabbaticals may find that the combination of a local wage and sabbatical pay would be sufficient to live adequately, if not luxuriously. While not all librarians could adapt easily to a year in a developing country, many would find it an adventure, and an opportunity well worth investigating.

\section{"Adopt an Archives" program}

The College and University Archives Section of the Society of American Archivists has established an informal "Adopt an Archives" program to match experienced college and university archivists with others requesting assistance. Each experienced archivist will provide free, informal advice (by mail or telephone) to one other person. The program is designed to foster one-to-one relationships among people from various institutions and geographical areas, and to involve more people in the work of the College and University Archives Section.

Since its inception eight matches have been made. Both "adoptors" and "adoptees" have been pleased with the outcome and recommend the program highly.

Individuals wishing to participate in the program, either as an adoptor or an adoptee, should contact the coordinator, Toby Murray, Archivist/Preservation Officer, McFarlin Library, University of Tulsa, 600 South College Avenue, Tulsa, OK 74104, (918) 592-6000, ext. 2864. 


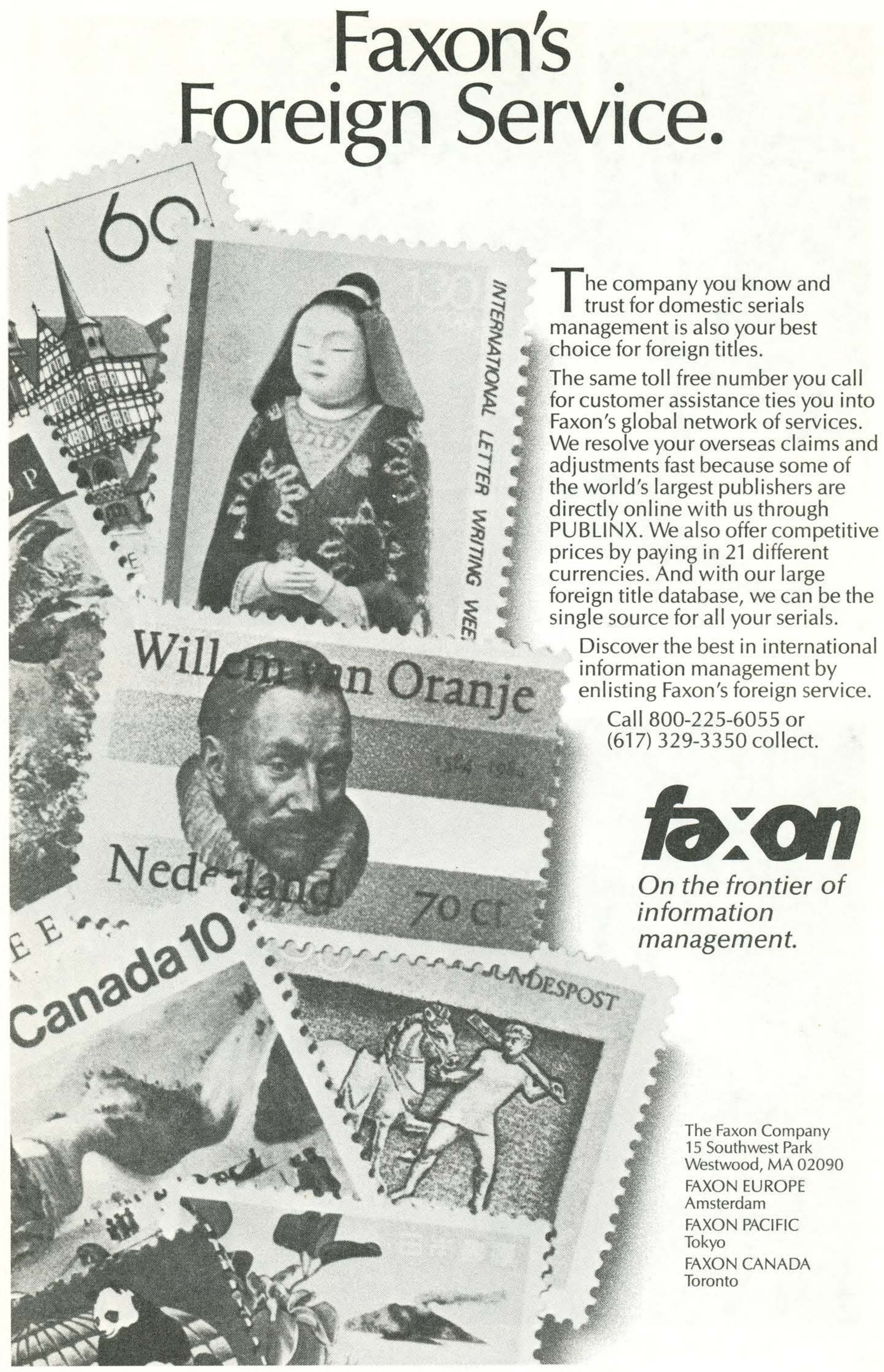




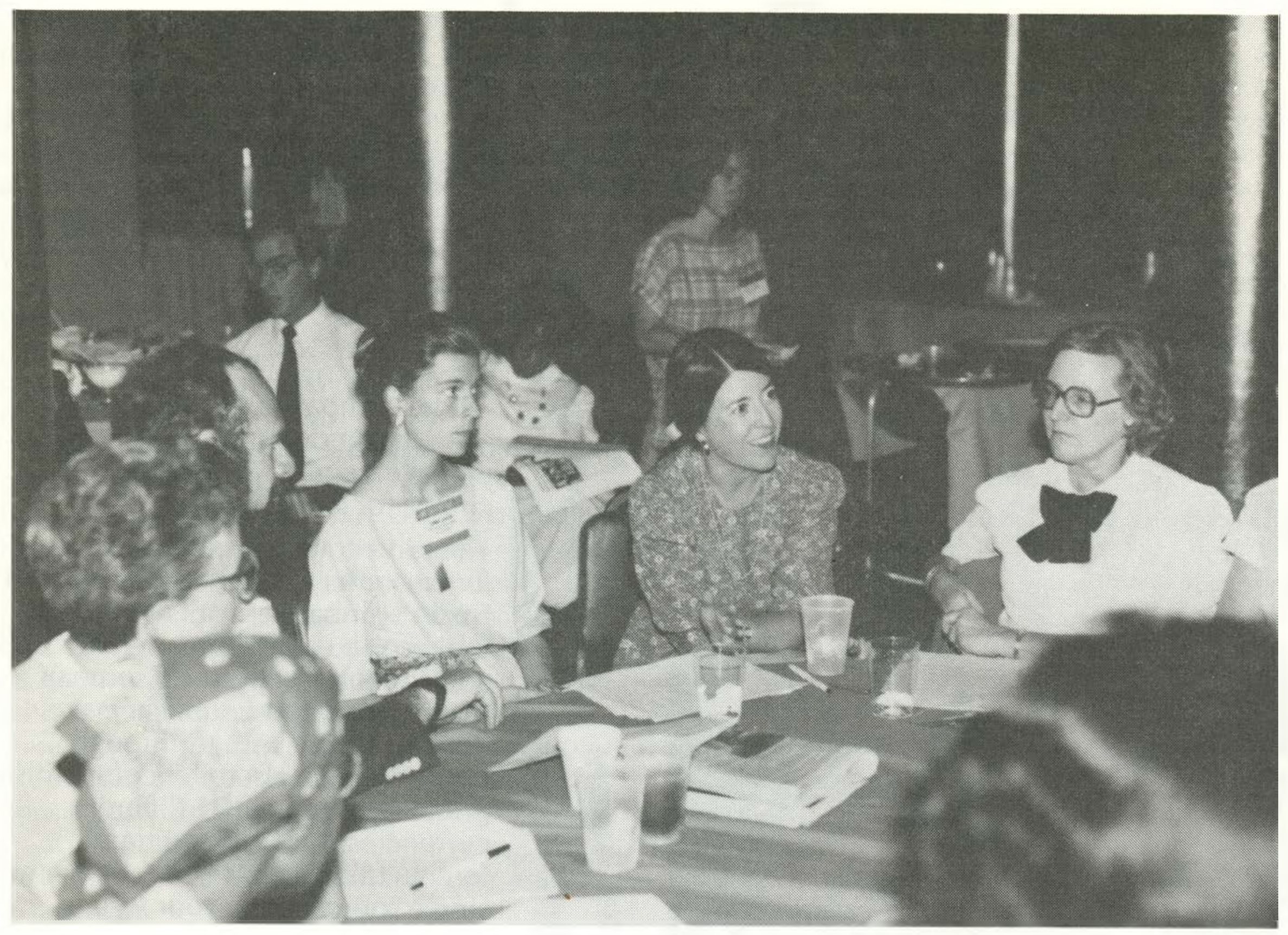

Incoming President Sharon Hogan discusses Association priorities at the ACRL President's Program at Annual Conference in Chicago.

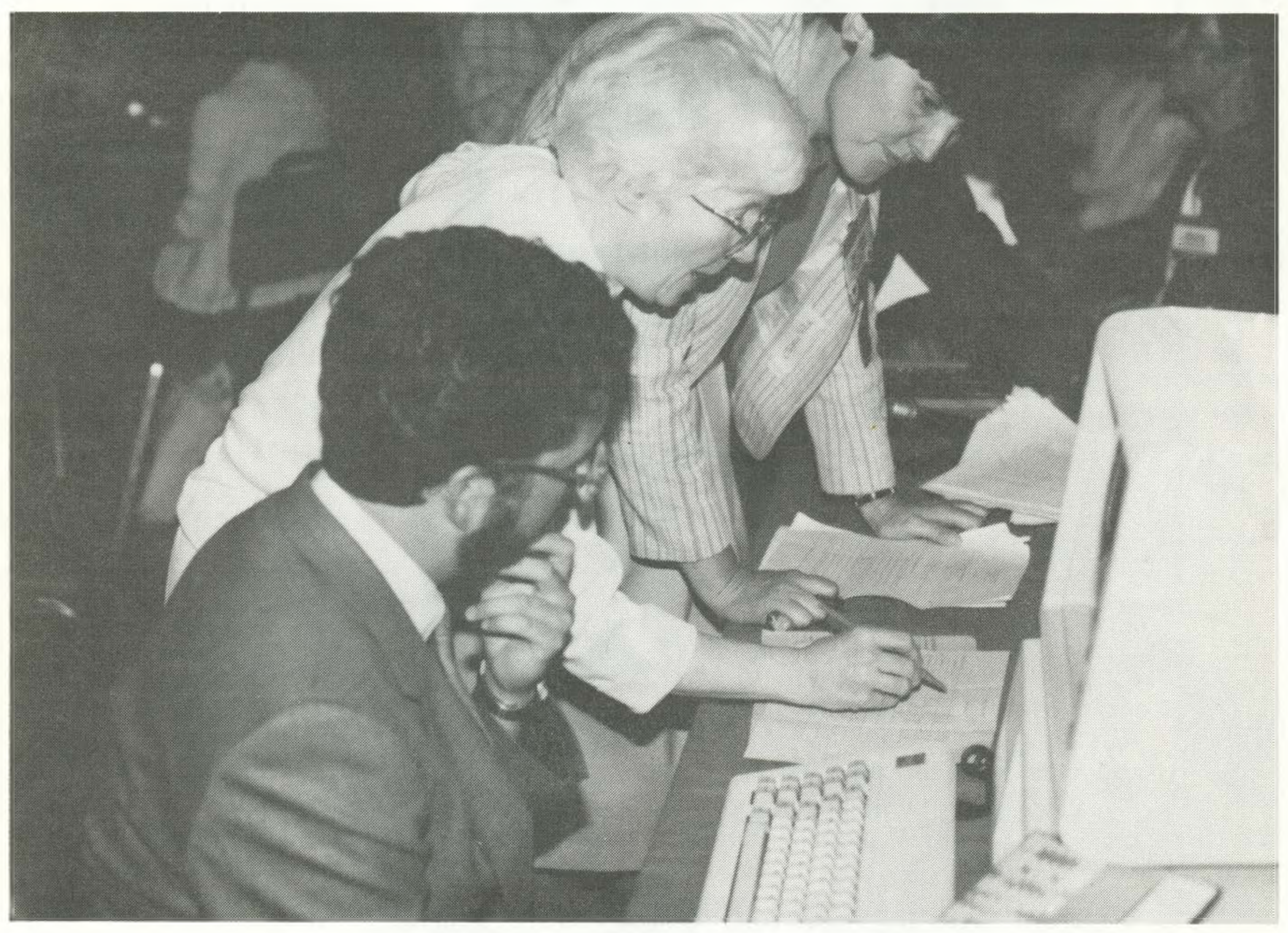

Brian Staples of OCLC, Inc., watches as JoAn Segal and Sandy Whiteley of ACRL prepare questionnaires for computer analysis. 